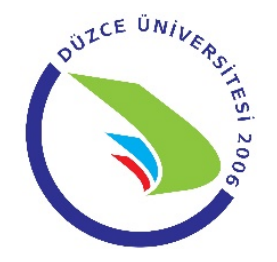

\title{
Gestasyonel Diyabet Görülme Sıklığı ve Anne-Bebek Sağlığı ile İlişkisi*
}

\author{
Raziye KAYA ${ }^{1}$, Zekiye KARAÇAM ${ }^{2}$
}

\section{ÖZ}

Amaç: $\mathrm{Bu}$ araştırma gestasyonel diyabetin görülme sıklığı ve anne-bebek sağlığı ile ilişkisini incelemek amacı ile yapılmıştır.

Gereç ve Yöntemler: Araştırma, analitik-kesitsel olarak, Haziran 2015 ve Eylül 2016 tarihleri arasında, İzmir Tepecik Eğitim ve Araştırma Hastanesi'nde doğum yapan 491 kadın ile gerçekleşmiştir. Veriler, araştırmacılar tarafından hazırlanan soru formu ile toplanmıştır. Verilerin analizinde tanımlayıcı istatistikler hesaplandıktan sonra Ki-kare, Student-t ve Mann-Whitney U testleri kullanılmıştır.

Bulgular: Araştırmaya katılan gebelerin \%8,1'ine gestasyonel diyabet tanısı konulduğu saptanmıştır. Gestasyonel diyabet görülme sıklı̆̆ının istatistiksel olarak anlamlı bir şekilde $25-45$ yaş aralığında $\left(\chi^{2}=18,232 ; p<0,001\right)$ ve ikinci derecede obez olanlarda $\left(\chi^{2}=12,457 ; \mathrm{p}=0,014\right)$ daha fazla görüldüğü bulunmuştur. Ayrıca gestasyonel diyabetin daha önceki gebeliklerinde $\left(\% 7,5\right.$ 'e karşı $\left.\% 1,1 ; \chi^{2}=5,801 ; p=0,016\right)$ ve aile $\left(\% 75,0\right.$ 'e karşı $\left.\% 22,0 ; \chi^{2}=53,379 ; p<0,001\right)$ öyküsünde diyabet ve daha önce 4000 gr üzerinde bebek doğumu (\%12,5'e karş1 $\left.\% 2,2 ; \chi^{2}=9,878 ; p=0,002\right)$ olan kadınlarda daha fazla görüldüğü ve bu farkların istatistiksel olarak anlamlı oldukları saptanmıştır. Gestasyonel diyabeti olan kadınların $(\% 27,5)$ gebelikleri boyunca diyabeti olmayanlara $(\% 8,9)$ göre daha fazla hastaneye yattıkları görülmüştür $\left(\chi^{2}=11,773 ; p=0,001\right)$. Yine gestasyonel diyabeti olan kadınların yenidoğanlarının vücut ağırlığı $(3345,88 \pm 588,43)$ ve göğüs çevresi ortalamalarının $(34,03 \pm 1,61)$ diyabeti olmayanlarınkilere göre $(3155,03 \pm 542,04$ ve $33,33 \pm 1,59$ ) daha fazla olduğu ve bu farkların da istatistiksel olarak önemli oldukları saptanmıştır (sırasıyla $\mathrm{t}=2,119$; $\mathrm{p}=0,035$ ve $\mathrm{t}=2,662 ; \mathrm{p}=0,009$ ).

Sonuç: $\mathrm{Bu}$ çalışmada gestasyonel diyabet görülme sıklığının yüksek olduğu, bu durumun kadınların gebelik süresince hastaneye yatış oranını ve bebeğin antropometrik ölçümlerini artırdığı sonuçlarına ulaşılmıştır. Sağlık çalışanları, yüksek gestasyonel diyabet riski bulunan gebeler başta olmak üzere tüm gebelerin gestasyonel diyabet konusunda bilgilendirmeleri, erken tanı için tarama testi yapılmasını sağlamaları, diyabet tanısı alan gebelere sağlıklı yaşam biçimi davranışlarını öğretmeleri ile anne-bebek sağlığına katkı sağlayabilirler.

Anahtar Kelimeler: Diyabet; gestasyonel; prevalans; bebek; kadın; sağlık; hemşirelik; bakım.

\section{Prevalence of Gestational Diabetes and Its Relation with Maternal-Infant Health}

\begin{abstract}
Aim: This study was conducted with the aim of investigating the incidence of gestational diabetes mellitus and maternal-infant health.

Material and Methods: The study was performed as analytical-cross sectional with 491 women who had given birth to their babies at İzmir Tepecik Training and Research Hospital between June 2015 and September 2016. Data were obtained by means of a questionnaire by the researcher. In the analysis of the data, descriptive statistics, Chi-square, Student-t and Mann-Whitney U tests were used.

Results: It was determined that $8.1 \%$ women who had participated the study was diagnosed with gestational diabetes. It was found out that the prevalence of gestational diabetes was statistically and significantly seen higher between 25-45 ages $\left(\chi^{2}=18.232 ; \mathrm{p}<0.001\right)$ and also in secondary obese people $\left(\chi^{2}=12.457 ; \mathrm{p}=0.014\right)$. In addition, it was established that gestational diabetes was more frequently observed in women with diabetes history in their previous pregnancies
\end{abstract}

1 Dokuz Eylül Üniversitesi, Araştırma ve Uygulama Hastanesi, İzmir, Türkiye

2 Adnan Menderes Üniversitesi, Sağlık Bilimleri Fakültesi, Ebelik Bölümü, Muğla, Türkiye

*Bu çalışma 22-24 Mart 2018 tarihleri arasında İstanbul'da gerçekleştirilen I. Uluslararası ve II. Ulusal Kadın Sağlığı Hemşireliği Kongresi'nde sözlü bildiri olarak sunulmuştur.

Sorumlu Yazar / Corresponding Author: Zekiye KARAÇAM, e-mail: zkaracam09@gmail.com Geliş Tarihi / Received: 21.02.2018, Kabul Tarihi / Accepted: 17.09.2018 
(7.5\% vs. $\left.1.1 \% ; \chi^{2}=5.801 ; \mathrm{p}=0.016\right)$ and family history (75.0\% vs. $22.0 \%$; $\chi^{2}=53.379 ; \mathrm{p}<0.001$ ) and in those with over 4000 gr baby delivery (12.5\% vs. $2.2 \%$; $\chi^{2}=9.878$; $\mathrm{p}=0.002)$ and these differences were statistically significant. It was seen that women with gestational diabetes (27.5\%) were more hospitalized than those without gestational diabetes (8.9\%) $\quad\left(\chi^{2}=11.773\right.$; $\mathrm{p}<0.001)$. It was also identified that the newborns of women with gestational diabetes had higher body weight (3345.88 \pm 588.43$)$ and their average chest girth (34.03 \pm 1.61$)$ and these differences were statistically important (respectively $\mathrm{t}=2.119 ; \mathrm{p}=0.035$ and $\mathrm{t}=2.662$; $\mathrm{p}=0.009$ ).

Conclusions: It was understood in this study that gestational diabetes rate was high and this situation increased hospitalization rate during pregnancy and anthropometric measurements of babies. Health professionals should inform all pregnant women about gestational diabetes including those with high gestational diabetes risk, provide screening test for early diagnosis, teach healthy life style behaviour to women diagnosed with diabetes and in this way, they can contribute to maternal-infant health.

Keywords: Diabetes; gestational; prevalence; infant; woman; health; nursing; care.

\section{GIRISS}

Diyabet, gebelikte sık karşılaşılan sistemik hastalıklardan biridir. Gebelik sırasında karşılaşılan diyabet hastalıklarının \%90'ını gestasyonel diyabetes mellitüs (GDM) ve \%10'unu pregestasyonel diyabetes mellitüs oluşturmaktadır (1). Ülkemizde de 2017 yılında 1291055 doğum gerçekleşmiştir (2). Bu gebeliklerin yaklaşık \%6,0'sında gestasyonel diyabet görüldüğü tahmin edilmektedir (3). GDM, ilk kez gebelik sırasında ortaya çıkan değişik derecelerde glikoz intoleransı olarak tanımlanmaktadır (4,5). GDM'nin anne sağlığı üzerine preeclampsia, sezaryen doğum ve daha sonraki yaşamda tip 2 diyabet riskinde artış gibi olumsuz etkileri bulunmaktadır $(6,7)$. GDM'li annelerin doğurdukları bebeklerde ise makrosomi, çocukluk çağı obezitesi, prediyabetes ve tip 2 diyabetes gelişme riskleri daha fazladır $(7,8)$. Gestasyonel diyabet sık karşılaşılması ve annebebek sağlığına olan olumsuz etkileri nedeni ile önemli bir sağlık sorunudur. Bu nedenlerle GDM, anne-bebek sağlığının yanında, gelecek nesiller ve toplum sağlığının korunması ve geliştirilmesi bağlamında dikkatle ele alınması ve daha fazla bilimsel araştırma yapılması gereken bir konudur.

Diyabet, insülin eksikliği ya da insülin etkisindeki defektler nedeniyle organizmanın karbonhidrat, yağ ve proteinlerden yeterince yararlanamadığı, sürekli tıbbi bakım gerektiren, kronik bir metabolizma hastalığıdır (9). GDM ise ilk kez gebelikte başlayan karbonhidrat intoleransı olarak tanımlanmaktadır $(10,11)$.

GDM'nin prevalansı kullanılan tanı test ve kriterlerinin yanı sıra toplumsal özelliklere göre değişiklik göstermektedir. The Centers for Disease Control and Prevention tarafindan 2014 yılı verilerine dayalı olarak yapılan analize göre, GDM prevalansının \%9,2 olduğu rapor edilmiştir (12). Türkiye'de ise değişik bölgelerde yapılan çalışmalarda GDM prevalansının \%2,6-27,9 arasında değiştiği görülmektedir (13-17).

GDM taramasında tek (75 gr OGTT) ve iki basamaklı (50 gr ve 75 gr ya da 100 gr OGTT) yöntemler olmak üzere iki farklı yaklaşım kullanılabilmektedir (18). Türkiye Endokrinoloji ve Metabolizma Derneği, fetüste makrozomi ve buna bağlı olarak gelişebilecek riskleri azaltmak, anne adayının sağlığını korumak ve ayrıca ileride gelişebilecek tip II diyabet ve insülin rezistansı açısından riskli kadınları izleyebilmek için tüm gebelerde 24. ve 28. haftalar arasında GDM taraması yapılmasını önermektedir. Bu taramada 50 gr glikoz içirildikten 1 . saat sonraki plazma glikozu 140-180 mg/dl bulunan kadınlara, GDM yönünden kesin tanı konulmak üzere 75 gr glikoz ile 2 saatlik OGTT yapılır. Elli gr glikoz ile tarama testinde 1 . saat plazma glikozu $\geq 180 \mathrm{mg} / \mathrm{dl}$ bulunması durumunda 75 gr glikoz ile OGTT yapılmasina gerek bulunmamaktadir. $\mathrm{Bu}$ gebelerin gestasyonel glikoz intoleransı olarak kabul edilmesi ve GDM gibi takip edilmesi gerekmektedir. Ayrıca GDM riski yüksek olan kadınlarda ön tarama testi olmaksızın doğrudan 75 gr glikoz ile OGTT yapılabilir (9).

GDM'nin anne ve bebek sağlığına olan riskleri konusunda çok sayıda uluslararası çalışma bulunmaktadır. $\mathrm{Bu}$ çalışmalarda GDM'nin annede preeklamsi, sezaryen ve müdahaleli doğum, tip II diyabet, üriner ve vajinal enfeksiyonlar, metobolik sorunlar, diyabetik vaskülopatilerin ilerlemesi, spontan abortus, preterm eylem, polihidroamnios, doğum travmaları, postpartum endometrit, yara enfeksiyonu ve maternal mortalite riskini artırdığı bildirilmektedir (19-21). GDM'nin fetüs ve yenidoğana olan riskleri ise perinatal mortalite, makrozomi, doğum travması, hiperbilirubinemi ve neonatal hipoglisemi, hiperglisemi, ketoasidoz, abortus, konjenital anomaliler, intrauterin ani fetal ölüm, gelişme geriliği, preterm doğum, respiratuar distress sendromu, dehidratasyon, polisitemi, hipomagnezemi, kardiyomiyopati, septal defekt, aort koarktasyonu, büyük damarlarda transpozisyon, hidrosefali, meningomyelosel, anensefali gibi konjenital anomaliler, öğrenme güçlükleri, çocuklukta obezite ve daha sonraki dönemde tip II diyabet görülme olarak rapor edilmiştir $(7,22,23)$.

GDM ile ilgili gebelik öncesi, gebelik, doğum ve doğum sonrası dönemlerde anne ve bebek sağlığının korunması ve geliştirilmesi için hemşire, ebe ve diğer sağlık çalışanlarının önemli sorumlulukları bulunmaktadır. GDM ile ilgili doğum öncesi bakım hizmetlerinin prekonsepsiyonel dönemde başlatılması gerekmektedir. $\mathrm{Bu}$ dönemde obez, GDM ve diyabetes mellitüs-DM öyküsü gibi yüksek risk grupları tespit edilmeli, koruyucu ve sağlığı geliştirici bakım hizmetleri verilmelidir. Antepartum bakımda, anne-bebek sağlığının en üst düzeyde olmasını sağlamak için gebelik süresince insülin ve glikozun fizyolojik dengesinin sürdürülmesi gerekmektedir $(24,25)$. Diyabetik gebelerin özel bir ekip (perinatolojist, diyabetalog, hemşire, ebe, diyetisyen) tarafindan izlenmesi, diyet, egzersiz, dinlenme, açlıktokluk kan şekerinin takibi, insülin kullanımı, hipoglisemi belirtileri, üriner sistem enfeksiyon belirtileri, hijyen ve bebek hareketlerinin izlenmesi konularında eğitim verilmesi gerekmektedir $(26,27)$.

Doğum eylemi süresince, maternal hiperglisemiden kaçınılması ve intrapartum glikoz seviyesinin 70-110 
$\mathrm{mg} / \mathrm{dl}$ düzeyinde tutulması gerekmektedir (28). Ayrıca bu gebelerin bebekleri de özel bakım ve izlem gerektirmektedir. Bebeğin hipogliseminin zararlı etkilerinden korunması için en kısa zamanda emzirilmesi ve hipoglisemi, hipokalsemi ve hiperbilirubinemi belirtilerinin izlenmesi gerekir (29). GDM'li anneye taburcu olmadan önce kan şekeri takibi, insülin dozu, diyeti, egzersizleri, emzirme, günlük bakımı, cinsel yaşamı ve kontrasepsiyon kullanımı konularında eğitim verilmelidir. Emziren annelerin günlük diyetine 300 kalori eklemek gerekir. Gece insülin dozu hipoglisemiyi önleyecek şekilde ayarlanmalıdır. $\mathrm{Bu}$ kadınların oral kontraseptifleri kullanmamaları, bariyer yöntemler ve koşulları uygunsa cerrahi sterilizasyonu kullanmaları uygun olabilir (29). Ayrıca GDM'li kadınların doğumdan 6-8. haftalardan sonra kalıcı diyabet yönünden izlenmesi gerekmektedir (30).

GDM anne-bebek sağlığına çok sayıda olumsuz etkisi olan önemli bir sağlık problemidir. Ancak literatürde, gestasyonel diyabet konusunda ülkemizde yapılan sınırlı sayıda çalışma olduğu görülmüş ve bu konuda bakım standartlarının geliştirilmesi için daha fazla güncel çalışma yapılmasına gereksinim duyulmuştur. $\mathrm{Bu}$ araştırmada gestasyonel diyabetin görülme sıklığı ve anne-bebek sağlığı ile ilişkisi incelenmiştir. Çalışmadan elde edilen bilgilerin gestasyonel diyabetin antepartum yönetimi, maternal ve fetal-neonatal olumsuz sonuçların önlenmesine katkı oluşturması beklenmektedir. Ayrıca bu araştırmanın sonuçları mevcut literatüre katkı sağlayabilir.

Araştırmanın amacı gestasyonel diyabetin görülme sıklığ ve anne-bebek sağlığı ile ilişkisinin incelenmesidir. Araştırmanın soruları; (i) gestasyonel diyabet görülme sıklığı nedir? (ii) Gestasyonel diyabet ile ilişkili faktörler nelerdir? (iii) Gestasyonel diyabetin anne sağlığ sonuçları ile ilişkisi nedir? (iv) Gestasyonel diyabetin bebek sağlığı sonuçları ile ilişkisi nedir? şeklinde siralanabilir.

\section{GEREÇ VE YÖNTEMLER}

$\mathrm{Bu}$ araştırma analitik ve kesitsel olarak, Haziran 2015 ve Eylül 2016 tarihleri arasında, İzmir ilinde bulunan İzmir Tepecik Eğitim ve Araştırma Hastanesi'nde kadın hastalıkları ve doğum servislerinde doğum yapan kadınlar ile gerçekleştirilmiştir.

\section{Araştırmanın Evreni ve Örneklemi}

Araştırmanın evrenini, 2014 yılı hastane kayıtlarına göre İzmir Tepecik Eğitim ve Araştırma Hastanesi'nde doğum yapan 10447 kadın oluşturmuştur. Örnekleme en az alınması gereken birey sayısı, Minitab 15 programı ile $\alpha=0,05, \quad p=0,09$ ve güç (power) $=0,80$ alınarak hesaplanmış ve 774 olarak bulunmuştur (31). Araştırmaya hastanenin yıllık hasta sayısı ve araştırmanın uygulamasına ayrılabilecek süre dikkate alınarak olasılıksız örnekleme (gelişi güzel) yöntemi ile belirlenen 850 kadının alınması planlanmıştır. Ancak çalışmanın izin aşamasının uzaması nedeniyle, verilerin toplanmasına ayrılan süre kısaltılmış ve araştırma 491 kişi ile tamamlanmıştır. $\mathrm{Bu}$ araştırma verilerine dayalı olarak yapılan analizde $\mathrm{G}^{*}$ power 3.1.9.2 ile power $=\% 80$ alfa $=0,05$, örneklem hacmi; 491 ve serbestlik derecesi 4 alınarak yapılan hesaplamada etki büyüklüğü 0,19 (küçük) bulunmuş ve örneklem hacminin yeterli olduğuna kanaat getirilmiştir.

Araştırmaya erken postpartum dönemde olan (doğum sonrası birinci gün), Türkçe konuşabilen ve anlayabilen kadınlar dâhil edilmiştir. Herhangi bir fiziksel, ruhsal ve zihinsel sağlık problemi öyküsü olan kadınlar örneklem kapsamı dışında bırakılmıştır.

\section{Araştırmada Etik}

Araştırma protokolü Adnan Menderes Üniversitesi Tıp Fakültesi Girişimsel Olmayan Klinik Araştırmalar Etik Kurulu tarafından onaylanmıştır (tarih: 09.07.2015; protokol no: 2015/605). Araştırma verilerinin İzmir ili Tepecik Eğitim ve Araştırma Hastanesi'nde doğum yapan kadınlardan toplanabilmesi için İzmir İli Kamu Hastaneler Birliği Genel Sekreterinden tarihinde yazılı izin alınmıştır (tarih: 28.09.2015; sayı: 67938315/799). Araştırma kapsamına alınan kadınlara araştırma ile ilgili bilgi verilmiş ve yazılı onamları alınmıştır.

\section{Veri Toplama Araçları}

Araştırma verileri araştırmacılar tarafından literatüre dayalı olarak hazırlanan Kadına Ait Bilgi Formu, Doğum ve Doğum Sonrası Dönem Anne ve Bebeğe Ait Bilgi Formu ve Gestasyonel Diyabete İlişkin Soru Formu ile toplanmıştır $(14,20,26,32,33)$. Bu formda kadınların sosyo-demografik özellikleri (yaş, eğitim durumu, eş eğitim durumu, gelir düzeyi, sağlık güvencesi, medeni durumu, kilo, boy, alışkanlıkları), gebelik sayısı, gebelik haftası, küretaj sayısı, ölü doğum sayısı, düşük sayısı, yaşayan çocuk sayısı, canlı doğum sayısı, daha önce hangi yolla doğum yaptığı, doğum şekli, gebelik öncesi kilosu, gebelikteki kilosu, boy uzunluğu, doğum öncesi eğitim alma, gebelik süresince sigara kullanma ve egzersiz yapma durumunu sorgulayan 27 soru bulunmaktadır. $\mathrm{Bu}$ form yüz-yüze görüşme yöntemi ile doldurulmuştur.

Doğum ve doğum sonrası dönem anne ve bebeğe ait bilgi formu, bebeğe ait bilgiler baş ve göğüs çevresi, kilosu, cinsiyeti, apgar skoru, doğum eylemi, doğum sonrası dönemde yenidoğanda ve annede gelişen komplikasyonlar, müdahale yapılma ve yoğun bakım ünitesine alınma durumunu sorgulayan 17 sorudan oluşmuştur. $\mathrm{Bu}$ formda yer alan verilerin bazıları yüz yüze görüşme yöntemi ile anneden, bazıları ölçüm yöntemi ve bazıları da hasta dosyasından elde edilmiştir. Gestasyonel diyabete ilişkin soru formu, ailede şeker hastalığı öyküsü, daha önceki gebeliklerde ve en son gebelikte GDM tanısı alma, tedavi şekli, gebelikten önce kan şekerinde yükselme, mevcut gebelikte erken doğum, polihidramnioz, intrauterin gelişme geriliği, makrozomik bebek öyküsü, gebelikte ya da öncesinde geçirilen hastalık varlığı, gebelikte, doğum sirasında ve doğum sonrasında sorun yaşama ile ilgili bilgileri sorgulayan toplam 19 sorudan oluşmaktadır. Bu formda yer alan bazı sorular yüz-yüze görüşme yöntemi ile doldurulmuş, bazıları da hasta dosyasında yer alan verilerden tamamlanmıştır.

\section{Ön Uygulama}

Soru formlarının anlaşılırlığı ve uygulanabilirliğini geliştirmek için doğum sonrası erken dönemdeki 10 kadın ile ön uygulama yapılmıştır. Bu uygulama sonunda soru formlarında değişiklik yapılmasına gereksinim duyulmamış ve ön uygulama yapılan kadınlar araştırma örneklemine dâhil edilmiştir. 


\section{Verilerin Toplanması}

Örnekleme alınan kadınlara çalışma hakkında bilgi verilmiş, çalışmaya davet edilmiş ve çalışmaya katılmaya kabul eden kadınların yazılı onamları alınmıştır. Veriler birinci araştırmacı tarafindan doğumdan sonra taburculuk döneminde olan annelerden yüz yüze görüşme, ölçüm yöntemleri ve hasta dosyasından elde edilmiştir. Veri toplama işlemi mahremiyete özen gösterilerek hasta odasında ve klinik işlerinin sakin olduğu zamanlarda yapılmıştır. Her bir soru formunun doldurulması yaklaşık 20-25 dakikada tamamlanmıștır.

\section{İstatistiksel Analiz}

Verilerin analizi 15.0 SPSS (PASW Inc., Chicago. IL. USA) paket programı ile analiz edilmiştir. Verilerin analizinde tanımlayıcı istatistikler (sayı, yüzde ve ortalama) hesaplanmış, ardından Ki-kare, Student-t ve Mann-Whitney U testleri kullanılmıştır. Üç ve daha fazla gruplarda yapılan Ki-kare analizinde, gruplar arasında fark saptandığında, farkın hangi gruptan kaynaklandığını belirlemek için gruplar ikili biçime indirgenmiş ve yeniden Ki-kare analizi yapılmıştır. Bu çalışmada $\mathrm{p}<0,05$ düzeyindeki değerler istatistiksel olarak anlamlı kabul edilmiştir. Ancak yapılan ileri analizler için önemlilik değeri: $p=0,05 /$ karşılaştırma sayısı formülü ile yeniden hesaplanmış ve ilgili değerler metin içinde verilmiştir (34).

\section{BULGULAR}

Araştırmaya katılan kadınların yaş ortalaması

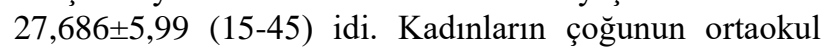
$(\% 28,3)$ ve lise $(\% 28,3)$ mezunu, $\% 91,2$ 'sinin ev hanımı olduğu ve $\% 8,1$ 'inin sağlık güvencesinin bulunmadığ saptanmıştır. Kadınların gelir durumu, sigara içme, egzersiz yapma, Beden Kitle İndeksi ve obstetrik özellikleri ile ilgili verileri Tablo 1'de verilmiştir. Kadınların \%29,1'inin gebeliklerini planlamadıkları, \%15,3'ünün doğum öncesi bakım almadıkları ve gebelikleri süresince ortalama 9,72 $\pm 4,08 \mathrm{~kg}$ (0-35) kilo aldıkları görülmüştür. Kadınların \%36,9'unun $(\mathrm{n}=181 / 491)$ vajinal doğum yaptığı, vajinal doğum yapan kadınların \%39,2'sinin $\quad(n=71 / 181) \quad$ doğumlarının indüksiyon ile başlatıldığ epizyotomi uygulandığ 1 ve $\% 23,8$ 'inde $(n=43 / 181)$ spontan laserasyon geliştiği belirlenmiştir (Tablo 1 ve Tablo 2).

Araştırmada bebeklerin kilo ortalamasının $3170,58 \pm 547,82$ (420-4800) ve \%5,5'inin 4000 gram üzerinde doğduğu belirlenmiştir. Bebeklerin baş çevresi ortalamasının $34,45 \pm 1,73 \mathrm{~cm}(21-38,5)$ ve göğ̈̈s çevresi ortalamasının $33,38 \pm 1,59 \quad \mathrm{~cm} \quad(28-38)$ olduğu saptanmıştır. Bazı bebeklerin yoğun bakımda olmaları nedeni ile baş çevresi $(\% 0,8 ; n=4 / 491)$ ve göğüs çevresi $(\% 2,8 ; n=14 / 491)$ bilgilerine ulaşılamamıştır. Bebeklerin \%9,1'inin $(n=45)$ birinci ve \%2,2'sini $(n=11)$ beşinci dakikalardaki APGAR skorlarının 3-6 arasında olduğu rapor edilmiştir (Tablo 2).

Ayrıca araştırmaya katılan kadınların \%42,2'sinin $(n=207 / 491)$ gebelikleri süresince GDM'den başka sorunlarının bulunduğu, \%5,1'inde $(n=25 / 491)$ doğum, \%3,1'inde $(n=15 / 491)$ doğum sonrası dönemde sağlık sorunu geliştiği gözlenmiştir. Bebeklerin \%26,3'ünde $(n=129 / 491)$ sağlık sorunu gözlendiği ve \%4,5'inin $(n=23 / 491)$ yenidoğan yoğun bakım ünitesine alındığı belirlenmiştir. Anne ve bebekte gelişen sorunlar Tablo 3 'te verilmiştir.

Tablo 1. Kadınların sosyo-demografik özellikleri $(\mathrm{n}=491)$

\begin{tabular}{|c|c|c|}
\hline Özellikler & Sayı (n) & Yüzde (\%) \\
\hline \multicolumn{3}{|l|}{ Yaş grupları } \\
\hline $15-24$ & 165 & 33,6 \\
\hline $25-34$ & 250 & 50,9 \\
\hline $35-45$ & 76 & 15,5 \\
\hline \multicolumn{3}{|l|}{ Eğitim durumu } \\
\hline Okur-yazar değil & 79 & 16,1 \\
\hline İlkokul & 115 & 23,4 \\
\hline Ortaokul & 139 & 28,3 \\
\hline Lise & 139 & 28,3 \\
\hline Ön lisans/lisans/lisansüstü & 19 & 5,6 \\
\hline \multicolumn{3}{|l|}{ Çalışma durumu } \\
\hline Ev hanımı & 448 & 91,2 \\
\hline Çalışan & 43 & 8,8 \\
\hline \multicolumn{3}{|l|}{ Algılanan gelir düzeyi } \\
\hline Gelir gidere göre düşük & 313 & 63,7 \\
\hline Gelir gider birbirine eşit & 178 & 36,3 \\
\hline \multicolumn{3}{|l|}{ Sağlık güvencesi } \\
\hline Yok & 40 & 8,1 \\
\hline Var & 451 & 91,9 \\
\hline \multicolumn{3}{|l|}{ Sigara içme durumu } \\
\hline Hayır & 406 & 82,7 \\
\hline Evet & 85 & 17,3 \\
\hline \multicolumn{3}{|l|}{ Egzersiz } \\
\hline Hayır & 440 & 89,6 \\
\hline Evet & 51 & 10,4 \\
\hline \multicolumn{3}{|l|}{ Beden kitle endeksi } \\
\hline Zayif & 13 & 2,6 \\
\hline Normal kilolu & 193 & 39,3 \\
\hline Fazla kilolu & 212 & 43,2 \\
\hline Birinci derece obez & 65 & 13,2 \\
\hline \multirow[t]{2}{*}{ İkinci derece obez } & 8 & 1,6 \\
\hline & Medyan & Min-Maks \\
\hline Gebelik sayısı & 2 & $1-12$ \\
\hline Doğum sayısı & 2 & $1-10$ \\
\hline Yaşayan çocuk sayısı & 2 & $1-10$ \\
\hline Spontan abortus & 1 & $1-6$ \\
\hline Küretaj sayısı & 1 & $1-3$ \\
\hline Ölü doğum & 1 & $1-3$ \\
\hline
\end{tabular}

GDM: Gestasyonel Diyabetes Mellitus, Min: Minimum, Maks: Maksimum

Araştırmaya katılan kadınların \%8,1'i (n=40/491) gestasyonel diyabet tanısı almışlardır. Kadınların GDM ile ilgili diğer verileri Tablo 4'te sunulmuştur. Gestasyonel diyabet görülme sıklığının yaş gruplarına göre yapılan istatistiksel analizinde gruplar arası fark önemli bulunmuştur $\left(\chi^{2}=18,232 ; \mathrm{p}<0,001\right)$. Yapılan ileri analizde bu farkın 15-24 ile 25-34 ve 35-45 yaş grupları arasındaki farktan kaynaklandığı saptanmıştır (sırasıyla $\chi^{2}=13,336 ; \mathrm{p}<0,001$ ve $\chi^{2}=20,208 ; \mathrm{p}<0,001$; Tablo 5). Kadınların beden kitle endeksi ile gestasyonel diyabet bulunma durumu karşılaştırıldığında gruplar arası fark önemli bulunmuştur $\left(\chi^{2}=12,457 ; \mathrm{p}=0,014>(0,05 / 10)\right)$. Yapılan ileri analizde bu farkın herhangi bir gruba bağlı olmadığ1 görülmüştür. Yine gestasyonel diyabeti olan 
Tablo 2. Kadınların gebelik, doğuma ve bebeklerine ilişkin verileri $(n=491)$

\begin{tabular}{|c|c|c|}
\hline Özellikler & Sayı (n) & $\%$ \\
\hline Gebeliği planlama durumu & 348 & 70,9 \\
\hline Doğum öncesi bakım alma durumu & 416 & 84,7 \\
\hline \multicolumn{3}{|l|}{ Gebelikte kilo alımı } \\
\hline $0-12$ & 386 & 78,6 \\
\hline $13-35$ & 105 & 21,4 \\
\hline \multicolumn{3}{|l|}{ Doğum şekli } \\
\hline Normal vajinal doğum & 181 & 36,9 \\
\hline Sezaryen & 310 & 63,1 \\
\hline \multicolumn{3}{|l|}{$\begin{array}{l}\text { Vaginal doğumların başlama şekli } \\
(n=181)\end{array}$} \\
\hline Spontan & 110 & 60,8 \\
\hline $\begin{array}{l}\text { Spontan } \\
\text { İndüksiyon ile }\end{array}$ & 71 & 39,2 \\
\hline Epizyotomi uygulaması $(\mathrm{n}=181)$ & 150 & 82,9 \\
\hline Laserasyon oluşma $(\mathrm{n}=181)$ & 43 & 23,8 \\
\hline \multicolumn{3}{|l|}{ Fetal Kalp Atımları } \\
\hline 116 & 1 & 0,2 \\
\hline $120-160$ & 463 & 94,3 \\
\hline $161-185$ & 27 & 5,5 \\
\hline \multicolumn{3}{|l|}{ APGAR skoru 1. dk. } \\
\hline $3-6$ & 45 & 9,1 \\
\hline $7-9$ & 446 & 90,9 \\
\hline \multicolumn{3}{|l|}{ APGAR skoru 5. dk. } \\
\hline $4-6$ & 11 & 2,2 \\
\hline $7-10$ & 480 & 97,8 \\
\hline \multicolumn{3}{|l|}{ Bebeğin doğum kilosu } \\
\hline $420-2490 \mathrm{~g}$ & 47 & 9,6 \\
\hline $2500-3000 \mathrm{~g}$ & 128 & 26,1 \\
\hline $3010-4000 \mathrm{~g}$ & 289 & 58,9 \\
\hline $4010-4800 \mathrm{~g}$ & 27 & 5,5 \\
\hline \multicolumn{3}{|l|}{ Baş çevresi } \\
\hline $21-32 \mathrm{~cm}$ & 40 & 8,1 \\
\hline $33-35 \mathrm{~cm}$ & 344 & 70,1 \\
\hline $36-38,5 \mathrm{~cm}$ & 103 & 21 \\
\hline Ölçülemeyen & 4 & 0,8 \\
\hline \multicolumn{3}{|l|}{ Göğüs çevresi } \\
\hline $28-30 \mathrm{~cm}$ & 27 & 5,5 \\
\hline $31-35 \mathrm{~cm}$ & 422 & 86 \\
\hline $35,5-38 \mathrm{~cm}$ & 28 & 5,7 \\
\hline Ölçülemeyen & 14 & 2,8 \\
\hline
\end{tabular}

kadınların istatistiksel olarak anlamlı bir şekilde gebelik süresince daha fazla hastaneye yattıkları (sırasıyla \%21,6'ya karşı \%6,6; $\chi^{2}=11,773 ; \mathrm{p}=0,001$; Tablo 5) belirlenmiştir.

GDM görülme sıklığının, GDM (\%37,5'e karşı \%7,7; $\left.\chi^{2}=5,801 ; \mathrm{p}=0,016\right)$, ailesinde diyabet $(\% 23,3$ 'e karş1 $\left.\% 2,8 ; \chi^{2}=53,379 ; \mathrm{p}<0,001\right)$ ve 4000 gramın üzerinde bebek doğurma (\%33,3'e karş1 $\left.\% 7,4 ; \chi^{2}=9,878 ; p=0,002\right)$ öyküsü bulunan kadınlarda, bulunmayanlara göre istatistiksel olarak anlamlı bir şekilde daha fazla olduğu görülmüştür. Yine gebeliklerinde diyabetten başka rahatsızlığı olanlarda (\%14,9'e karşı \%4,6; $\chi^{2}=15,478$, $\mathrm{p}<0,001)$ ve gebelik, doğum ve doğum sonras1 dönemlerde bebeklerinde sağlik problemi bulunanlarda (\%19,7'e karşı \%4,5; $\left.\chi^{2}=27,201 ; \mathrm{p}<0,001\right)$ olmayanlara göre istatistiksel olarak anlamlı bir şekilde daha fazla oranda gestasyonel diyabet görülmüştür (Tablo 5).
Tablo 3. Gebelik, doğum ve doğum sonrası anne ve bebekte gelişen sorunlar $(n=491)$

\begin{tabular}{lcc}
\hline Özellikler & Sayı (n) & $\mathbf{( \% )}$ \\
\hline Gebelikte diyabetten başka sorun bulunma & $\mathbf{2 0 7}$ & $\mathbf{4 2 , 2}$ \\
\hline Gebelikte yaşanan GDM dişı sorunlar & &
\end{tabular}
$(\mathrm{n}=207)$

İdrar yolu hastalıkları 88

Erken doğum 44

Hipertansiyon 25

Bebekte gelisim geriliği $\quad 23 \quad 12,1$

Polihidroamnios $18 \quad 18$

Preeklemsi $\quad 4 \quad 0,9$

Oligohidroamnios $\quad 2 \quad 0,5$

Psikolojik sorunlar $\quad 1 \quad 0,5$

Eklampsi $\quad 1 \quad 10,5$

Plasenta previa

\begin{tabular}{lll}
\hline Annede doğum sirasında problem gelişme & 25 & 5,1 \\
\hline
\end{tabular}

Annede doğum sırasında gelişen problemler

Hipertansiyon

Solunum sikıntısı

Solunum sıkıntısı ve hipertansiyon

Hiperglisemi

Hipotansiyon ve hipoglisemi

Solunum sıkıntısı, yüzde siyanoz ve hipertansiyon

\begin{tabular}{lll}
\hline Annede doğum sonrasında problem gelişme & 15 & 3,1 \\
\hline
\end{tabular}

Annede doğum sonrasında gelişen

problemler

Hipertansiyon

Solunum sikıntısı

Karaciğer fonksiyon bozukluğu

$10 \quad 66,7$

\begin{tabular}{lll}
\hline Bebekte sağlık sorunu bulunma & 129 & 26,3 \\
\hline Bebek sağlığı ile ilgili gelişen problemler & &
\end{tabular}

$(n=129)$

Erken doğum 43

Normalden iri bebek $\quad 30$

33,4

Normalden iri bebek

23,4

Solunum sikintis

15,6

İntrauterin gelişim geriliği

Bebekte kan şekerinin düşük olması

7,0

Doğumsal anomaliler

Sarılık

Omuz takılması

İntrauterin asfiksi

İmmün trombositopenik purpura

Kardiyak problemler

Serebral enfarktüs

Kafatası büyüklüğü

Yoğun bakıma alınma

5,4

4,8

4,8

1,6

1,6

0,8

0,8

0,8

Yoğun bakıma alınma nedenleri $(n=23)$

Prematüre

Solunum s1kintıs1

Prematüre, solunum sıkıntısı ve kardiyak

problemler

Kardiyak problemler

Kan uyuşmazlığ 1

Siyanoz

Sarılık

Prematüre, solunum sıkıntısı ve entübasyon

GDM: Gestasyonel Diyabetes Mellitus 
Araştırmada GDM'li kadınların bebeklerinin kilo $(3345,88 \pm 588,43)$ ve baş çevresi $(34,03 \pm 1,61)$ ortalamalarının GDM'si olmayanlara göre (sirasiyla $3155,03 \pm 542,04$ ve $33,33 \pm 1,59)$ daha yüksek olduğu ve bu farkın istatistiksel olarak da anlamlı olduğu saptanmıştır (sırasıyla $\mathrm{t}=2,119 ; \mathrm{p}=0,035 ; \mathrm{t}=2,662$; $\mathrm{p}=0,009$; Tablo 5).

Tablo 4. Kadınların gestasyonel diyabete ilişkin verileri $(\mathrm{n}=491)$

\begin{tabular}{|c|c|c|}
\hline Özellikler & $\begin{array}{c}\text { Sayı } \\
\text { (n) }\end{array}$ & $\begin{array}{c}\text { Yüzde } \\
(\%)\end{array}$ \\
\hline Gebelikte diyabet tanis1 alma & 40 & 8,1 \\
\hline Şeker yükleme testi yaptırma & 305 & 62,1 \\
\hline \multicolumn{3}{|l|}{ Kullandıkları şeker yükleme testi } \\
\hline 50 gr şeker yükleme testi & 224 & 45,6 \\
\hline 75 gr şeker yükleme testi & 72 & 14,7 \\
\hline 50 gr +100 gr şeker yükleme testi & 7 & 1,4 \\
\hline Bilmiyor & 2 & 0,4 \\
\hline \multicolumn{3}{|l|}{ GDM tanisı koyulma haftası $(n=40)$} \\
\hline 24-28. haftalarda & 39 & 97,5 \\
\hline 29-37. haftalarda & 1 & 2,5 \\
\hline \multicolumn{3}{|l|}{$\begin{array}{l}\text { Gebelikte diyabet tanı yöntemi } \\
(\mathrm{n}=40)\end{array}$} \\
\hline Şeker yükleme testi & 39 & 97,5 \\
\hline Kan şekeri ölçümü takibi & 1 & 2,5 \\
\hline \multicolumn{3}{|l|}{ GDM için uygulanan tedavi $(n=40)$} \\
\hline Diyet & 24 & 60 \\
\hline İnsülin & 7 & 17,5 \\
\hline Diyet ve egzersiz & 5 & 12,5 \\
\hline Diyet ve insülin & 4 & 10 \\
\hline Ailede diyabet öyküsü & 129 & 26,3 \\
\hline \multicolumn{3}{|l|}{$\begin{array}{l}\text { Ailede diyabet hastalığı bulunan } \\
\text { kişiler ( } \mathrm{n}=129)\end{array}$} \\
\hline Anne & 80 & 62 \\
\hline Baba & 22 & 17 \\
\hline Anne ve baba & 17 & 13,2 \\
\hline Anne ve kardeş & 4 & 3,1 \\
\hline Anne ve baba ve kardeş & 3 & 2,3 \\
\hline Kardeş & 2 & 1,5 \\
\hline Teyze ve anneanne & 1 & 0,8 \\
\hline $\begin{array}{l}\text { Daha önce } 4000 \text { gr üzerinde bebek } \\
\text { doğurma }\end{array}$ & 15 & 3,1 \\
\hline $\begin{array}{l}\text { Diyabetli gebelere eğitim verilme } \\
\text { durumu }(\mathrm{n}=40)\end{array}$ & 38 & 95,0 \\
\hline \multicolumn{3}{|l|}{ Eğitim veren kişi $(n=38)$} \\
\hline $\begin{array}{l}\text { Doktor/Hemşire/ Diyabet } \\
\text { hemsiresi }\end{array}$ & 27 & 71,1 \\
\hline $\begin{array}{l}\text { nemşıres1 } \\
\text { Doktor/Hemșire }\end{array}$ & 4 & 10,5 \\
\hline Doktor/Diyabet hemșiresi & 4 & 10,5 \\
\hline Doktor & 2 & 5,3 \\
\hline Doktor/Diyetisyen & 1 & 2,6 \\
\hline
\end{tabular}

GDM: Gestasyonel Diyabetes Mellitus

\section{TARTISSMA}

$\mathrm{Bu}$ araştırma İzmir il merkezinde gestasyonel diyabetin görülme sıklığ1 ve anne-bebek sağlığ 1 ile ilişkisini incelemek amacıyla yapılmıştır. Çalışmada gestasyonel diyabeti olan kadınlara ilişkin önemli ulusal veriler ortaya koyulmuştur.

\section{GDM prevalansı}

Araştırmada GDM prevalansının (\%8), Türkiye'de yapılan çalışmaların sonuçlarını yansıtan bir sistematik derlemede bildirilen (\%6) orandan daha yüksek olduğu görülmüştür (3). Bu oran Avrupa ülkelerinde yapılan çalışmaların dâhil edildiği bir meta analizde de \%5,4 (18) ve Amerika Birleşik Devletleri'nde, \%5-7 (6) olarak bildirilmiştir. $\mathrm{Bu}$ sonuçlar gebelerin önemli bir bölümünde gestasyonel diyabet geliştiğini göstermektedir.

\section{GDM ile ilişkili faktörler}

$\mathrm{Bu}$ araştırmada gestasyonel diyabetin kadınların yaşı, beden kitle endeksi, ailesinde diyabet, GDM ve 4000 gr üzerinde bebek doğurma öyküleri ile ilişkili olduğu görülmüştür. $\mathrm{Bu}$ sonuçlar ülkemizde ve diğer ülkelerde yapılan diğer bazı araştırmaların sonuçları ile benzerlik göstermektedir $(3,7,18,22,23,33,35,36)$. Bu sonuçlara göre bu ilişkili durumlara sahip olan gebelerin GDM yönünden dikkatle izlenmesi gerektiği söylenebilir.

Araştırmada kadınların ikametgâh, eğitim durumu, çalışma durumu, algılanan gelir düzeyi, sigara içme durumu, egzersiz ile ilgili verilerin gestasyonel diyabet üzerindeki etkisinin olmadığı görülmüştür. Özgül ve ark (38)'nın yaptığı çalışmada da benzer olarak sigara kullanımının gestasyonel diyabet üzerinde etkisinin olmadığ1 rapor edilmiştir. Tobias ve ark (39)'nın yaptıkları bir meta-analiz çalışmasında ise bizim bulguların aksine, gebelik öncesinde fiziksel aktivite yapan kadınlarda GDM görülme oranının daha düşük olduğu bildirilmiştir. Diğer bazı çalışmalarda da yine GDM'un düzenli fiziksel egzersiz yapma ile ilişkili olduğu belirtilmiştir $(7,22,23)$. DeSisto ve ark. (40) ve Feleke (23) yaptıkları çalışmalarda ise eğitim düzeyi ile GDM arasında ilişkinin bulunduğunu rapor etmişlerdir. $\mathrm{Bu}$ sonuçlara göre bazı sosyo-kültürel değişkenlerin GDM gelişimini etkilediği ve bu etkilenmenin toplumsal durumlara göre değişiklik gösterdiği akla gelebilir.

\section{GDM'nin anne sağlığı sonuçları ile ilişkisi}

Çalışmada GDM'si olan kadınların daha fazla oranda gebelik sırasında başka sağlık sorunları ile karşılaştıkları görülmüştür. $\mathrm{Bu}$ durum GDM'nin gebelikte sağlık problemi geliştirmesi ile ilişkili olabilir.

$\mathrm{Bu}$ araştırmada gestasyonel diyabeti olan kadınların çoğunun sezaryen ile doğum yaptıkları görülmüştür. Ülkemizde yapılan diğer çalışmalarda da benzer bulgular sunulmuştur $(38,41)$. Diğer ülkelerde yapılan bazı çalışmalarda ise benzer olarak GDM'nin sezaryen doğum riskini artırdığı bildirilmiştir $(7,22,23)$. Bu sonuçların aksine Özyurt ve ark. (17) ve Bakırcı (42) çalışmalarında gestasyonel diyabeti olan kadınların sezaryenle doğum yapma oranlarının daha düşük olduğunu belirtmişlerdir. $\mathrm{Bu}$ sonuçlar, gestasyonel diyabetli kadınların doğum şeklinin sağlık çalışanlarının tutumuna bağlı olarak bölgesel farklılık gösterdiğini düşündürmektedir.

$\mathrm{Bu}$ araştırmada GDM'nin doğumun başlama şekli, epizyotomi ve laserasyon bulunma durumlarını etkilemediği görülmüştür. Özgül ve ark. (38)'nın yaptığı çalışmada da benzer sonuçlar bildirilmiştir. Diğer yandan iri bebek doğuran kadınlarda vajinal epizyotominin uzamas1, vajinal laserasyonlar, postpartum atoni gibi durumlar daha sık gözlenebilir (38). $\mathrm{Bu}$ sonuçlar bu konuda daha fazla çalışma yapılması gerektiğini ortaya koymaktadır. 
Tablo 5. Kadınların bireysel ve bebeklerin bazı özelliklerinin gestasyonel diyabet bulunma durumuna göre dağılımı $(\mathrm{n}=491)$

\begin{tabular}{|c|c|c|c|}
\hline \multirow[b]{2}{*}{ Değişkenler } & \multicolumn{2}{|c|}{$\begin{array}{l}\text { Gestasyonel Diyabet } \\
\end{array}$} & \multirow{2}{*}{$\begin{array}{l}\text { Test istatistiği ve } \\
\text { p değerleri }\end{array}$} \\
\hline & Var n (\%) & Yok n (\%) & \\
\hline \multicolumn{4}{|l|}{ Yaş grupları } \\
\hline $15-24$ & $2(1,2)$ & $163(98,8)$ & 18,232 / <0,001 \\
\hline $25-34$ & $26(10,4)$ & $224(89,6)$ & \\
\hline $35-45$ & $12(15,8)$ & $64(84,2)$ & \\
\hline \multicolumn{4}{|l|}{ Eğitim durumu } \\
\hline Okur-yazar değil/ilkokul & $17(8,8)$ & $177(91,2)$ & \\
\hline Ortaokul & $14(10,1)$ & $125(89,9)$ & $2,055 / 0,358$ \\
\hline Lise/ön lisans/lisans/lisansüstü & $9(5,7)$ & $149(94,3)$ & \\
\hline Ev hanımı olma & $38(8,5)$ & $410(91,5)$ & $0,343 / 0,558$ \\
\hline Düşük gelir düzeyi & $24(7,7)$ & $289(92,3)$ & $0,265 / 0,607$ \\
\hline Sağlık güvencesinin olmaması & $0(0)$ & $40(100)$ & 2,768 / 0,096 \\
\hline Sigara içen & $6(7,1)$ & $79(92,9)$ & $0,163 / 0,687$ \\
\hline Egzersiz yapan & $6(11,8)$ & $45(88,2)$ & $0,529 / 0,464$ \\
\hline \multicolumn{4}{|l|}{ Beden kitle endeksi } \\
\hline Zayıf & $0(0)$ & $13(100)$ & \\
\hline Normal kilolu & $11(5,7)$ & $182(94,3)$ & \\
\hline Fazla kilolu & $19(9)$ & $193(91,0)$ & 12,457 / 0,014 \\
\hline Birinci derece obez & $6(9,2)$ & $59(90,8)$ & \\
\hline İkinci derece obez & $3(37,5)$ & $5(62,5)$ & \\
\hline Gebelikten önce sağlık sorunu bulunma & $1(11,1)$ & $8(88,9)$ & $0,000 / 1,000$ \\
\hline Daha önceki gebeliklerde diyabet öyküsü & $3(37,5)$ & $5(62,5)$ & $5,801 / 0,016$ \\
\hline Ailede diyabet öyküsü & $30(23,3)$ & $99(76,7)$ & $53,379 /<0,001$ \\
\hline Gebelikte diyabetten başka sağlık sorunu & $25(14,9)$ & $143(85,1)$ & $15,478 /<0,001$ \\
\hline $\begin{array}{l}\text { Gebelikte, doğumda, doğum sonrası dönemde } \\
\text { bebekte problem gelişme }\end{array}$ & $23(19,7)$ & $94(80,3)$ & $27,201 /<0,001$ \\
\hline Daha önce 4000 gr üzerinde bebek doğurma & $5(33,3)$ & $10(66,7)$ & $9,878 / 0,002$ \\
\hline Doğum öncesi bakım almama & $3(4)$ & $72(96)$ & $2,034 / 0,154$ \\
\hline Gebelikte hastaneye yatma & $11(21,6)$ & $40(78,4)$ & $11,773 / 0,001$ \\
\hline Sezaryen doğum & $30(9,7)$ & $280(90,3)$ & $2,633 / 0,105$ \\
\hline Doğumun indüksiyon ile başlatılması & $5(7,0)$ & $66(93,0)$ & $0,148 / 0,700$ \\
\hline Epizyotomi uygulaması & $9(6,0)$ & $141(94,0)$ & $0,034 / 0,854$ \\
\hline Spontan laserasyon & $4(9,3)$ & $39(90,7)$ & $0,739 / 0,390$ \\
\hline Annede doğum sirasında problem gelişme & $4(16)$ & $21(84)$ & $1,206 / 0,272$ \\
\hline Annede doğum sonrasında problem gelişme & $2(13,3)$ & $13(86,7)$ & $0,071 / 0,790$ \\
\hline FKA anormal değerler & $0(0)$ & $28(100)$ & $1,606 / 0,205$ \\
\hline 1.dk Apgar skoru: 3-6 & $5(11,1)$ & $40(88,9)$ & $0,227 / 0,633$ \\
\hline 5.dk Apgar skoru: 4-6 & $0(0)$ & $11(100)$ & $0,195 / 0,659$ \\
\hline Kilo, ortalama \pm SS & $3345,88 \pm 588,43$ & $3155,03 \pm 542,04$ & $2,119 / 0,035$ \\
\hline Göğüs çevresi, ortalama $\pm S S$ & $34,03 \pm 1,61$ & $33,33 \pm 1,59$ & $2,662 / 0,009$ \\
\hline Baş çevresi, Ortalama/Rankların toplamı & $281,29 / 11251,50$ & $240,66 / 107576,50$ & $-1,810 / 0,070$ \\
\hline Yoğun bakıma alınma sayısı & $1(4,3)$ & $22(95,7)$ & $0,085 / 0,770$ \\
\hline
\end{tabular}

FKA: Fetal kalp atımı, SS: Standart Sapma

\section{Araştırmanın sınırlılıkları}

$\mathrm{Bu}$ araştırmanın bazı sınırlılıkları bulunmaktadır. Birincisi, araştırma kesitsel olarak ve olasılıksız (gelişi güzel) örnekleme yöntemi ile belirlenen kadınlarda yapılmıştır. Bu nedenle, elde edilen sonuçlar zamana bağlı olarak değişebilir, araştırmaya katılan kadınları temsil etmektedir ve genellenemez. İkincisi, araştırmanın bazı verileri kadınların öz bildirimlerine dayalı olarak elde edilmiştir ve verilerin güvenilirliği, kadınların verdiği bilgiler ile sınırlıdır. Üçüncüsü, bu çalışmada gestasyonel diyabet sıklığı, araştırmanın yapıldığ hastanede rutin olarak uygulanan iki aşamalı test (50 ve 75 gr OGTT) sonuçları ve ADA (American Diabetes Association) tanı kriterine göre belirlenmiştir. Elde edilen sonuçlar, diğer test ve tanı kriterlerine göre yapılan değerlendirmelerden farklı olabilir.

\section{SONUÇ VE ÖNERILER}

$\mathrm{Bu}$ araştırma, gebelerin \%8'inde gestasyonel diyabet geliştiği sonucunu ortaya koymuştur. Yine çalışmada, GDM’nin görülme sıklığının 25 yaş ve üzerinde, ikinci derece obez, diyabetten başka hastalığına sahip olma, daha önceki gebeliklerinde gestasyonel diyabet, ailede diyabet ve 4000 gramın üzerinde bebek doğurma öyküsü, yenidoğanların kilo ve göğüs çevresi ortalamaları ile ilişkili olduğu açığa çıkarılmıştır. Diğer yandan araştırmada GDM'si olan kadınların gebelik sırasında daha fazla başka sağlık sorunları ile karşılaştıkları, ancak bebeklerin APGAR skoru ve yenidoğan yoğun bakım 
ünitesine alınma durumlarını etkilemediği sonuçları elde edilmiştir.

Araştırmadan elde edilen sonuçlara dayalı olarak; (a) sağlık çalışanlarının gestasyonel diyabet bakımından yüksek riskli olan gebeler başta olmak üzere tüm gebelere gestasyonel diyabet ile ilgili bilgi vermeleri, erken tanı için tarama testi yapılmasını sağlamaları, diyabet tanısı alan gebelere sağlıklı yaşam biçimi davranışlarını öğretmeleri, bu gebeleri ve bebeklerini gebelik, doğum ve doğum sonrası dönemde yakın izlemeleri, bireysel bakımı planlamaları ve uygulamaları, (b) örgün ve yaygın eğitim birimlerinde görevli hemşire ve ebelerin bu ve diğer çalışmaların sonuçlarını dikkate alacak biçimde eğitim programlarını yenilemeleri ve bu konudaki farkındalıklarının artırılması, (c) sağlık yöneticilerinin gestasyonel diyabet ile ilgili kanıta dayalı uygulamalarını ve bilimsel bilgi gelişimini geliştirecek biçimde düzenleme yapmaları, (ç) gestasyonel diyabete ilişkin daha kapsamlı verileri ortaya koyabilecek gözlemsel, gestasyonel diyabetli kadınların ve bebeklerinin sağlık durumunu geliştirebilecek yöntemlerin test edildiği deneysel ve gestasyonel diyabetli kadınların deneyimlerini ortaya koyabilecek kalitatif araştırmaların yapılması önerilebilir.

\section{Teşekkür}

$\mathrm{Bu}$ araştırma Adnan Menderes Üniversitesi Sağlık Bilimleri Enstitüsü Doğum, Kadın Sağlığı ve Hastalıkları Hemşireliği Anabilim Dalı Yüksek Lisans Tezi olarak yapılmıştır. Araştırmamıza katkı sağlayan tüm kadınlara ve araştırmanın yürütüldüğü hastane yönetici ve çalışanlarına sonsuz teşekkürlerimizi sunarız.

\section{Araştırmanın Fonu}

$\mathrm{Bu}$ araştırma Adnan Menderes Üniversitesi Bilimsel Araştırma Projeleri tarafından desteklenmiştir (Proje No: ASYO-16006).

\section{KAYNAKLAR}

1. Özuğuz U, Aydın Y, Berker D. Gestasyonel diyabet: Risk faktörleri, tanı ve tedavi. İç Hastalıkları Dergisi. 2010;17(2): 71-9.

2. Türkiye İstatistik Kurumu Haber Bülteni [Internet] [Son güncelleme tarihi: 6 Temmuz 2018; Erişim tarihi: 1 Ağustos 2018]. Erişim adresi: http://www.tuik.gov.tr/PreHaberBultenleri.do?id=275 89.

3. Çelik D, Karaçam Z. Türkiye'de gestasyonel diyabetes mellitus prevalansı ve risk faktörleri: Sistematik derleme ve meta analiz. Adnan Menseres Üniversitesi 1. Sağlık Bilimleri Kongresi; 29 Haziran1 Temmuz 2017; Aydın; 2017. s.802.

4. Ovayolu N, Ovayolu Ö. Patofizyoloji. Adana: Adana Ziraat Grup Matbaacilık; 2016.

5. Padmapriya N, Bernard JY, Liang S, Loy SL, Cai S, Zhe IS, et al. Associations of physical activity and sedentary behavior during pregnancy with gestational diabetes mellitus among Asian women in Singapore. BMC Pregnancy Childbirth. 2017; 17(1): 364-74.

6. Abebe KZ, Scifres C, Simhan HN, Day N, Catalano $\mathrm{P}$, Bodnar LM, et al. Comparison of two screening strategies for Gestational Diabetes (GDM2) Trial:
Design and rationale. Contemp Clin Trials. 2017; 62(1): 43-9.

7. Sugiyama MS, Cash HL, Roseveare C, Reklai R, Basilius K, Madraisau S. Assessment of gestational diabetes and associated risk factors and outcomes in the Pacific Island Nation of Palau. Matern Child Health J. 2017; 21(10): 1961-6.

8. Jeppesen C1, Maindal HT, Kristensen JK, Ovesen PG, Witte DR. National study of the prevalence of gestational diabetes mellitus among Danish women from 2004 to 2012. Scand J Public Health. 2017; 45(8): 811-7.

9. Satman İ, İmamoğlu Ş, Yılmaz C, Akalın S, Salman S. Diabetes mellitus ve komplikasyonlarının tanı, tedavi ve izlem k1lavuzu. Ankara: Türkiye Endokrinoloji ve Metabolizma Derneği; 2016.

10. Metzger BE, Gabbe SG, Persson B, Buchanan TA, Catalano PA, Damm P, et al. International Association of Diabetes and Pregnancy Study Groups recommendations on the diagnosis and classification of hyperglycemia in pregnancy: International Association of Diabetes and Pregnancy Study Groups Consensus Panel. Diabetes Care. 2010; 33(7): 676-82.

11. Hartling L, Dryden DM, Guthrie A, Muise M, Vandermeer B, Aktary WM, et al. Screening and diagnosing gestational diabetes mellitus. Evid Rep Technol Assess (Full Rep). 2012; 210(1): 1-327.

12. American Diabetes Association [Internet]. USA: What is Gestational Diabetes? [Cited: 2018 Jan 1]. Available from: http://www.diabetes.org/diabetesbasics/gestational/what-is-gestational-diabetes.html.

13. Aktün LH, Uyan D, Yorgunlar B, Acet $M$. Gestational diabetes mellitus screening and outcomes. J Turk Ger Gynecol Assoc. 2015;16(1): 25-9.

14. Aydın M, Gürel A, Çelik C, Tülübaş F, Abalı R, Yılmaz A. Namık Kemal Üniversitesi Araştırma ve Uygulama Hastanesinde gestasyonel diyabetes mellitus prevalansı. Yeni Tıp Dergisi. 2013; 30(3): 252-4.

15. Akgöl E, Abuşoğlu S, Gün FD, Ünlü A. Prevalence of gestational diabetes mellitus according to the different criterias. Turk J Obstet Gynecol. 2017; 14(1): 18-22.

16. Balık G, Şahin Baydur S, Tekin Bayoğlu Y, Şentürk Ş, Kağıtcı M, Şahin Kır F. The prevalence of gestational diabetes mellitus in pregnants who applied to the maternity outpatient clinic of a university hospital. Ege Journal of Medicine. 2016; 55(2): 55-8.

17. Özyurt R, Aşıcıoğlu O, Gültekin T, Güngördük K, Boran B. İstanbul Eğitim ve Araştırma Hastanesi Kadın Hastalıkları ve Doğum Kliniği'ne başvuran gebelerde gestasyonel diyabet sıklığı. Jinekoloji Obstetrik Pediatri ve Pediatrik Cerrahi Dergisi. 2013; 5(1): 7-12.

18. Eades CE, Cameron DM, Evans JMM. Prevalence of gestational diabetes mellitus in Europe: A metaanalysis. Diabetes Res Clin Pract. 2017; 129(7): 17381.

19. Kwong W, Tomlinson G, Feig D. Gestational diabetes and other obstetrical outcomes after bariatric surgery: A systematic review and meta-analysis. Diabetes. 2016; 40(1): 2-20.

20. Saxena P, Tyagi S, Prakash A, Nigam A, Trivedi SS. Pregnancy outcome of women with gestational 
diabetes in a tertiary level hospital of North India. Indian J Community Med. 2011; 36(2): 120-3.

21. Pandey U, Agrawal KN, Agawal S, Batra S. Outcome of diabetic pregnanciens in a tertiary referral centre Varanasi. J Obstet Gynecol India. 2016; 66(4): 22632.

22. Reichelt AJ, Weinert LS, Mastella LS, Gnielka V, Campos MA, Hirakata VN, et al. Clinical characteristics of women with gestational diabetescomparison of two cohorts enrolled 20 years apart in southern Brazil. Sao Paulo Med J. 2017; 135(4): 37682.

23. Feleke BE. Determinants of gestational diabetes mellitus: A case-control study. J Matern Fetal Neonatal Med. 2018; 31(19): 2584-9.

24. Brown J, Alwan NA, West J, Brown S, McKinlay CJD, Farrar D, et al. Lifestyle interventions for the treatment of women with gestational diabetes. Cochrane Database of Syst Rev. 2017; (5): CD011970.

25. World Health Organization [Internet]. Geneva: Global report on diabetes [Cited: 2018 Jan 27]. Available from:http://apps.who.int/iris/bitstream/10665/204871/ 1/9789241565257_eng.pdf.

26. Hartling L, Dryden DM, Guthrie A, Muise M, Vandermeer B, Donovan L. Benefits and harms of treating gestational diabetes mellitus: A systematic review and meta-analysis for the U.S. Preventive Services Task Force and the National Institutes of Health Office of Medical Applications of Research. Ann Intern Med. 2013; 159(2): 123-9.

27. Ural A. Gestasyonel diabetes mellitus ve sağlıklı yaşam biçimi davranışları. Düzce Üniversitesi Sağlık Bilimleri Enstitüsü Dergisi. 2016; 6(2): 120-7.

28. beslenme.gov.tr [Internet]. Ankara: Türkiye diyabet programı 2015-2020. Türkiye Halk Sağlığ1 Kurumu; 2014 [Son güncelleme tarihi: 2014; Erişim tarihi: 10.02.2017]. Erişim adresi: http://beslenme.gov.tr/content/files/diyabet/turkiyediy abetprogrami.pdf.

29. Coşkun A. Kadın Sağlığı ve Hastalıkları Hemşireliği El Kitabı. İstanbul: Koç Üniversitesi Yayınları; 2012.

30. sbu.saglil.gov.tr [Internet]. Ankara: Riskli Gebelikler Yönetim Rehberi. Türkiye Halk Sağlığı Kurumu Kadın ve Üreme Sağlığı Daire Başkanlığı; 2014. 2014 [Son güncelleme tarihi: 2014; Erişim tarihi: 10.02.2017]. Erişim adresi: http://sbu.saglik.gov.tr/Ekutuphane/kitaplar/risgebyon reh.pdf.

31. Özdamar K. SPSS ile Biyoistatistik. Eskişehir: ETAM A.Ş. Matbaa Tesisleri; 2003.

32. Kutay GN, Gönenç G, İşçi H, Yiğiter AB. Dünder İ. Gestasyonel diabetes mellitus riskinin maternal yaş ve gebeliğin başlangıcındaki vücut kitle indeksi ile ilişkisi. Dicle Tıp Dergisi. 2013; 40(3): 406-9.

33. Özdemir Ö, Sarı ME, Ertuğrul FA, Şakar VS, Özcanlı G, Atalay C. Prevalence of Gestational Diabetes Among Pregnant Women Attending Ankara Numune Training Hospital and Research Hospital. Turkiye Klinikleri J Gynecol Obst. 2014; 24(1): 24-9.

34. Cangur S, Ankaralı H. Examining the Probabilities of Type I Error for Unadjusted All Pairwise Comparisons and Bonferroni Adjustment Approaches in Hypothesis Testing for Proportions. Int J Stat Med Res. 2014; 3(4): 404-11.

35. Tonguc M, Tayyar AT, Muderris I, Bayram F, Muhtaroglu S, Tayyar M. An evaluation of two different screening criteria in gestational diabetes mellitus. J Matern Fetal Neonatal Med. 2018; 31(9): 1188-93.

36. Avcı Eftal M, Şanlıkan F, Çelik M, Avcı A, Kocaer M, Göçmen A. Effects of Maternal Obesity on Antenatal, Perinatal and Neonatal Outcomes. J Matern Fetal Neonatal Med. 2015; 28(17): 2080-3.

37. Lynes C, McLain AC, Yeung EH, Albert P, Liu J, Boghossian NS. Interpregnancy weight change and adverse maternal outcomes: A retrospective cohort study. Ann Epidemiol. 2017; 27(10): 632-7.

38. Özgül G, Melekoğlu R, Yeleç S, Eskiyörük İ, Özgünen FT. Borderline gestasyonel diabetes mellitus saptanan gebelerin perinatal sonuçları. Perinatoloji Dergisi. 2015; 23(1): 6-12.

39. Tobias DK, Zhang C, Vandam RM, Bowers K, Hu FB. Physical activity before and during pregnancy and risk of gestational diabetes mellitus. Diabetes Care. 2011; 34(1): 223-9.

40. DeSisto CL, Kim SY, Sharma AJ. Preventing Chronic Disease: Prevalence estimates of gestational diabetes mellitus in the United States, Pregnancy Risk Assessment Monitoring System (PRAMS), 20072010. Preventing Chronic Disease. 2014;11: E104. doi: http://dx.doi.org/10.5888/pcd11.130415.

41. Karabayır N, Atalay C, Adal E, Önal H. Diyabetik anne çocuklarında morbidite. JOPP Dergisi. 2011; 3(3): 139-46.

42. Bakırcı G. Ankara Atatürk Eğitim ve Araştırma Hastanesi Gebe Polikliniğinde Gestasyonel Diyabet Taraması İçin Yapılan 50 Gram Oral Glukoz Tolerans Testi Sonuçlarının Değerlendirilmesi [Uzmanlık Tezi]. Ankara: Ankara Atatürk Eğitim ve Araştırma Hastanesi; 2015. 